\title{
Helpers influence on territory use and maintenance in Alpine marmot groups.
}

Cristian Pasquaretta, Laura Busia, Caterina Ferrari, Giuseppe Bogliani, Denis Réale \& Achaz von Hardenberg

\begin{abstract}
In social mammals, territory size and shape vary according to the number and strength of neighbour individuals competing for resources. Two main theories have been proposed to explain this variability: the Group Augmentation (GA) and the realized Resource Holding Potential (rRHP) hypotheses. The first states that the outcome of the interactions among groups depends on the total number of individuals in the group while the second states that only the number of animals directly involved in intergroup competition determines this outcome. We collected data on space use of individually tagged Alpine marmots ( Marmota marmota), a cooperative breeding species that overlaps part of its territory with neighbouring groups. In accordance with the rRHP hypothesis, we found that groups having higher proportion of helpers, rather than higher total number of individuals, had lower percentage of the territory overlapping with neighbouring groups and a larger area available for individual exclusive use.
\end{abstract}




\section{Introduction}

Competition for resources is one of the most important factors delineating territories of neighbouring groups in many social animals. Adams (2001) reviewed experimental and theoretical works on home range and territory size, and showed that interactions among neighbouring individuals or groups directly shape their territory boundaries. Two main hypotheses have been proposed to explain the outcome of intergroup competition: the Group Augmentation hypothesis (GA: Kokko et al. 2001; Bergmüller et al. 2007) and the realized Resource Holding Potential (rRHP) hypothesis (Crofoot et al. 2008). Group Augmentation states that the increased number of individuals in a group should increase individual fitness and give advantage to the entire group in more densely occupied territories. The rRHP hypothesis, instead, states that the strength of a group should primarily depends on the actual number of individuals directly involved in the competition rather than on the total number of individuals perse.

Cooperative breeding mammals are among the best subjects to study intergroup competition because they live in groups of variable size, and each individual can potentially develop particular social competences (Taborsky et al. 2012). Cooperative breeding is a reproductive system in which one or more members of the group (i.e. helpers) take care of young that are not their own direct offspring (Solomon \& French 1997). As reviewed by Bergmüller et al. (2007) indirect fitness benefits due to kinship with the dominant pair cannot fully explain the evolutionary stability of cooperation and direct benefits for the non-reproductive individuals can also play an important role. For example helpers can enhance their own future fitness by inheriting part or the whole territory that belongs to the dominant pair or by dispersing to neighbouring territories as soon as these territories become vacant (Cockburn 1998). 
Benefits for the dominant pair may include active cooperation of the helpers in territory defence during intergroup aggression and their participation in the maintenance of territory boundaries using marking behaviours (reviewed by Heap et al. 2012). Scent marking behaviours - i.e. the deposition of gland secretion, faeces or urine on territory spots of particular interest can vary in time and space usually increasing during the breeding season (e.g. Canis latrans: Gese \& Ruff 1997; Marmota monax: Maher 2004; Lynx lynx Vogt et al. 2014). Furthermore, scent marks can have different functions depending on where they occur: close to the boundaries they serve as territory signals (e.g. Ourebia ourebi: Brashares \& Arcese 1999; Propithecus verreauxi: Benadi et al. 2008; Canis simensis: Sillero-Zubiri \& Macdonald 1998; Saguinus mystax: Gosling \& Roberts 2001) while in the core of the territory they can be involved as a signal of social dominance towards subordinates (Ralls 1971; Jordan et al. 2010). For example scent marking is used to establish and maintain social dominance in yellow-bellied marmot (Armitage 1976) and its social function directly depends on where the behaviour is performed (Brady \& Armitage 1999).

In this study we used data collected on a population of free living Alpine marmots (Marmota marmota) to 1) verify the function of scent marking behaviours, 2) estimate the helper role in territorial task, and 3) perform a comparative test of the rRHP and the GA hypotheses in a cooperative breeding species. Alpine marmot provides an excellent model species for studying these questions: they breed cooperatively, (i.e. sub-dominant males help by increasing pups survival during winter; Allainé \& Thureau 2004), they actively defend their territories overlapping part of them with neighbours (Perrin 1993b) and they use scent-marking behaviours for territory defence (Lenti Boero 1995). Interestingly, whereas the role of helpers in territorial defence has been shown in many species (Lazaro-Perea 2001; Bruintjes \& Taborsky 2008; Le Vin et al. 2011), direct evidences of their involvement in supporting the rRHP or the GA hypothesis are missing. 
In particular we evaluated the role of scent marking in territorial defence in Alpine marmots by looking at where the behaviour was primarily performed (i.e. close to the boundaries or to the centre of the territory) and if it was directly related to the proportion of overlap areas with neighbouring groups. Large overlap areas are expected to decrease individual benefits both directly (e.g. smaller individual growth rate: Anolis aeneus Stamps 1984) as well as indirectly (e.g. smaller mean area available for individual exclusive use Gaston 1978). In addition we estimated the impact of helpers (i.e. males $>2$ years old, see Arnold 1990) on group territoriality by analysing their involvement in scent marking behaviour in respect to other age and sexclasses.

Finally, we tested the rRHP against the GA hypothesis by investigating the effects of having a large number of helpers, instead of individuals of all age and sex classes, in a group on the inter-annual size variation of the overlap area between two neighbouring groups (hereafter called dyad). Furthermore, to evaluate the possible impact of helpers on neighbours group density, we calculated the proportion of area available for individual exclusive use in each group sharing part of its territory with neighbours. According to the GA hypothesis we expected that both the mean area available for individual exclusive use and the proportion of overlap areas among groups are mostly influenced by the differences in the total number of individuals present in each group. In contrast, the rRHP hypothesis predicts that both the mean area available for individual exclusive use and the proportion of overlap areas among groups are mostly influenced by the difference in the number of helpers. We took into account the presence of young of the year in each group to weight for the actual motivation of the helpers to increase their inclusive fitness (Hamilton 1964). Finally we investigated the effect of the year (i.e. 2009 and 2010), the presence of pups, the number of individuals, and the proportion of adult males (i.e. both dominant and helpers) in each group on territory size. 


\section{Methods}

Study area

This study was conducted on two sub-populations of Alpine marmot in the area of

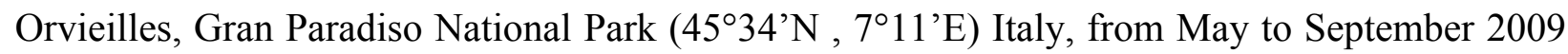
and 2010. The first site is located at about 2100 m.a.s.l. and characterized by an ecotone between the tree line and the alpine grassland; the second one is an open site located at about 2300 m.a.s.l.. Vegetation consisted of alpine meadows. Natural predators, such as golden eagles (Aquila chrysaetos) and red foxes (Vulpes vulpes), were present in the study area, and predation risk was variable depending on the site (Ferrari et al. 2009).

\section{Study species}

Alpine marmots are a burrow-dwelling rodents that inhabit alpine meadows and grasslands, ranging from medium to high altitudes (i.e. between 1400 and $2700 \mathrm{~m}$.), in the European Alps, the Pyrenees, the Carpathians and the Apennines. Like all the species of the genus Marmota, Alpine marmots hibernate during the winter, and the active season usually starts in April and lasts until October, depending on climate conditions (Zelenka 1965). Alpine marmots are cooperative breeders (Allainé \& Theuriau 2004) that form family groups of up to 20 individuals (Arnold \& Dittami 1997), generally made of a pair of dominant individuals, subordinate adults and yearlings, and young of the year (Arnold 1990; Allainé 2000). Dominants generally inhibit the reproduction of subordinates (Arnold \& Dittami 1997; Hackländer et al. 2003). Helpers delay dispersal (Blumstein \& Armitage 1999) and their presence in the natal group increases the juveniles' survival during the winter (Allainé \& Thureau 2004). Male sex- 
bias at weaning has been reported in Alpine marmots (Allainé 2000) and females born in a malebiased litter show a higher probability of becoming dominant in the future (Hackländer \& Arnold 2012). Alpine marmots are diurnal and the groups occupy relatively small and stable territories (Perrin et al 1993b; Pasquaretta et al. 2012). They are, therefore, easy to observe. They defend a group territory (Perrin et al. 1993a), and territorial behaviours mainly occur during the breeding season (Bel et al. 1995). Although aggressive behavioural displays rarely injure the opponent seriously, fights can sometimes be deadly (Ferrari et al. 2012).

From 2007 to 2010, we have live-trapped 149 different individuals using 19 Tomahawk traps $(150$ x 30 x $30 \mathrm{~cm}$, Tomahawk Live Traps, Hazelhurst, WI, U.S.A.). We located the traps near the burrows entrances with food baits (salad and flowers) to attract marmots. We constantly observed all the traps at a minimum distance of 300 meters. Once an individual was trapped two operators transferred it from the cage into an handling bag and transported it to the handling area where all the capture protocol was then executed $(17 \pm 5$ min was the mean time $( \pm$ SD) from the capture to the first manipulation). Individuals were marked with two plastic ear tags (Minirototag, Ghislandi \& Ghislandi, Bergamo, Lombardy, Italy) with different colour combinations. We used a black dye used for human hair to bleach the fur of marmots and thus to aid invisual recognition at a distance. While collecting biometrical measures we applied the dye to a specific part of the back of the individual (left leg, right leg or back). We then accurately washed the fur before releasing the animal. We never observed any behavioural reaction by conspecifics to the presence ear tags or fur bleaching of marked marmots. Individuals not captured as pups were aged based on their weight (i.e. yearlings can be easily distinguished from adults), and sexed based on their ano-genital distance (Zelenka 1965). We assigned three different age classes established by the individual trapping history for each recognised animal: "pup" (born during the current year, mean weight \pm SD: $0.52 \pm 0.2 \mathrm{~kg}$ ), "yearling" (1 year old, $1.69 \pm 0.4 \mathrm{~kg})$, and "adult" ( $\geq 2$ years of age, $3.42 \pm 0.7 \mathrm{~kg})$. 


\section{Field data collection}

We used two observation points (one per study area) located at a minimum distance of 100 meters from the closest group to avoid potential disturbance arising from the presence of the researchers (Crofoot et al. 2010). We collected 2454 spatial locations for 58 individuals (i.e. 21 females and 37 males), belonging to 9 different groups in 2009 (mean fixes per group = 266; range $=101-390)$ and 2374 spatial locations for 56 individuals (i.e. 21 females and 35 males) belonging to 10 different groups in 2010 (mean fixes per group $=229$; range $=48-432$ ), using the scan sampling method (Altmann 1974; Martin \& Bateson 1993) and the Animal Locator tool (Pasquaretta et al. 2012) which allows the collection of accurate distance, angle and inclination of an individual in respect to a fixed observation point. Observations were always conducted by two observers: one who was responsible for locating the individuals by using binoculars and the Animal Locator tool and the other who identified each marmot using a spotting scope thanks to the unique ear tag colour combination for each individual. We recorded the current activity of each individual (i.e. foraging, looking around, looking from the burrow, greeting, grooming, playing, marking, fighting, general movement, and other, see Barash 1989). We collected the data every 45 minutes and we tested independence of the data applying a Moran autocorrelation test (Gittleman \& Kot 1990) to 435 individual matrices where positions of each individual were at least collected for 3 consecutive scans (i.e. 1 hour and an half). Time needed to collect spatial data for all aboveground marmots in view was $15 \pm 3 \min ( \pm$ s.e.). The observers were continuously watching the animals without losing contact with them during the interval between two scans. By using this methodology, we are confident that the probability of not sighting an animal aboveground is close to zero. Scan sampling started at 6:00 am and finished at 7:00 pm with a break between 1:00 to $3.00 \mathrm{pm}$, when marmots decreased their activity above ground. 


\section{Data analysis}

\section{Territory size:}

We calculated the territory size and shape using the kernel.area and the kernelUD functions in the R package "adehabitat" (Calenge 2006; R Development Core Team 2011). We used the Kernel Density Estimator (KDE), representing the intensity with which a given area is used (Fieberg \& Kochanny 2005), because it allows for the estimation of multiple centres of activities (Worton 1989; Kernohan et al. 2001). However, KDE is sensitive to the choice of the smoothing parameter $h$ (Fieberg 2007). The most often used method for selecting the $h$ parameter is the Least Square Cross Validation (LSCV) method. Nevertheless it suffers from large possible biases when applied to clumped data such as those collected for animals with a central burrow system (Hemson et al. 2005). We, thus, decided to apply the href method (Worton 1995). The href method can also be biased from potential over-smoothing (Seaman \& Powell 1996) but it is more adapted to clumped data. In the present work we used the $90 \%$ isopleths (Börger et al. 2006) to reduce its possible over-smoothing.

Territory centre (i.e. geographic centre, see Maher 2009), shape, and size were calculated for each group at any period. The mean number of localisations per group in the three periods was 52 fixes for the first, 129 fixes for the second, and 82 fixes for the third period. The number of fixes collected ranged from 11 to 107 , from 23 to 226 and from 31 to 156 for the first, the second, and the third period respectively. Groups with less than 10 points for each period were not included in the analysis (Börger et al. 2006). Geographic centres of each member of the group were calculated using the arithmetic mean of their positions. 


\section{Scent marking:}

To test for seasonal variation in the frequencies of scent marking behaviour we divided each active season into three sub-periods corresponding to 1) post-hibernation (from mid-May to emergence of the first pup i.e.: 26th of June), 2) pup emergence (from the 27 th to the first of August) and 3) pre-hibernation (from mid-August to mid-September). For each period and each group, we also calculated the distance between scent marking locations and both the geographic centre and boundaries of the group. We collected 207 scent marking behaviours during the study using the scan sampling procedure described above; we only recorded the first occurrence of the marking behaviour to avoid collecting repeated measures during the same behavioural display. Groups contributed differently to the dataset collected having a mean of 10 scent marking activities per group each year ranging from 0 to 21 marking behaviours. We assigned a value of 0 when the distance of the marking behaviour from the centre was shorter than the distance of the marking behaviour from the boundaries of the group and a value of 1 in the opposite case.

\section{Space use:}

To evaluate the effect of helpers on the overlap areas, we estimated the proportion of area shared by each group calculating the ratio between their overlap area and territory size (Fieberg \& Kochanny 2005) using the kerneloverlap function in the "adehabitat" R package. Territorial aggressive interactions usually occurred between animals of two different social groups (Pasquaretta pers. obs.). We consequently used family dyads as case units, and we removed from the analysis data collected when more than two groups were involved in the interaction. We obtained a relative Index of Overlap as the differences between the overlap areas of the two groups involved in the dyad applying the following formula: 
It should be noted that $\operatorname{Overlap}_{(\mathrm{i}, \mathrm{j})}$ is a common area of intersection for the two groups in the dyad. From the equation it can be derived that Overlap Index is equal to the difference of the inverse of the territory size of two neighbour groups, and it allows us to estimate a weighted value of overlap area based on the territory size of the two groups involved. Moreover, we calculate a relative mean area available for individual exclusive use between dyads as the inverse of the differences of their mean areas available for individual exclusive use.

For each group we calculated a "Male Index" as the percentage of adult males on the total number of adults present in the group. We then calculated a "balanced Male Index" (balanced MI) for each dyad as the ratio of the two male indices of each group of the dyad. The balanced MI is $>1$ if the first group had a higher percentage of adult males than the second one. We also created a "Young Index", divided in four categories, between two neighbouring groups as follow: A having no young and B having young (A_no-B_yes); A and B both having no young (A_no - B_no); $\mathrm{A}$ and B both having young (A_yes - B_yes); A having young and B having no young (A_yes - B_no). We finally calculated the ratio of the total number of individuals (Group Index) between dyads. All analyses were performed on 11 different groups.

\section{Statistical analysis:}

We evaluated possible biases in territory size estimation due to the variability in the number of fixes collected. We then tested the effect of year, presence of pups, seasonal periods, total number of individuals (i.e. all age and sex classes), and proportion of adult males in the group on territory size using linear mixed-models (LME) including group as random effect. We decided to run different models for each predictor to avoid problems related to the use of a high number of parameters with a small number of cases (i.e. small number of dyads involved in the analysis). 
We analysed the relationship between the proportion of overlap areas and the proportion of time spent marking the territory to evaluate the reliability of using variation in overlap areas as a proxy of territorial behaviour in our species. We then used a Chi-squared test to evaluate whether scent-marking behaviour usually occurred close to the territory boundaries rather than to the centre. Moreover we tested differences in scent marking behaviour between sexes and among ages and seasonal periods by running three Bayesian Markov Chain Monte Carlo models for categorical data using individual identity nested in group and year as random effects (package MCMCglmm in R, Hadfield 2010).

In order to test for the Group Augmentation (i.e. influence of total number of individuals) and the RHP hypotheses (i.e. influence of the helper category) we performed multi-model selection on two different linear mixed models: one having the relative Overlap Index and the other the relative mean area available for individual exclusive use for each dyad as response variables. Multi-model inference is a statistical technique used to compare candidate models and rank them according to the Akaike Information Criterion (Akaike 1985) corrected for small sample sizes (AICc) and their normalized Akaike weights (AICw) (Burnham \& Anderson 2002). When the candidate models differed in AICc by 2 units, we accepted the one with the lowest AICc as the best fitting model but considered other acceptable models in the discussion. Multimodel selections were run using the R Package MuMIn (Barton 2009). We used balanced Male Index, Group Index, their interaction, Young Index and study site as fixed effects in both models. Because we had partially nested data (e.g. 8 groups occupied the same area during two following years while others changed), and because we had repeated measures during the same year (i.e. three periods for each dyad), we included group identity nested in group dyads within year as random effects in the models. We implemented models using the LME function in nlme package of R (Pinheiro and Bates 2000). Alpha significant level was set at 0.05. All analyses were 
performed in the open-source statistical environment $\mathrm{R}$ version 3.1.2 ( $\mathrm{R}$ Development Core Team 2014).

\section{Results}

Spatial data were independent: Moran test was significant only for 20 cases out of 435 . Mean territory size was $1.40( \pm 0.66 \mathrm{SD})$ hectares over the two years $(\mathrm{n}=17)$. We did not find any influence of the number of locations collected on territory size (LME, 95\% CI: $-0.001-$ $\left.0.006 ; F_{1,36}=3.39, P=0.074\right)$. Density of individuals in each group varied among territories (mean $=6.42 \pm 4.51$ individuals per hectare), but territory size was stable between years (LME, 95\% CI: $-0.028-0.621 ; F_{2,37}=3.29, P=0.079$ ), between groups with or without pups (LME, 95\% CI: $-0.554-0.424 ; F_{2,37}=0.07, P=0.790$ ), and among the three periods (LME, 95\% CI: $\left.0.291-0.102 ; F_{3,36}=1.35, P=0.273\right)$. Territory size was neither significantly related to group size (LME, 95\% CI: $\left.-0.126-0.081 ; F_{1,37}=0.19, P=0.661\right)$ nor to male index (LME, 95\% CI: $\left.-0.922-1.818 ; F_{1,37}=0.44, P=0.512\right)$.

The proportion of overlap areas was positively related to the proportion of marking behaviours (LME, $F_{1,32}=38.95, P<0.001$; Fig. 1). Adult individuals showed a higher percentage of marking behaviours than yearlings and pups (Table 1a). Frequency of scentmarking the territory was significantly higher in males than in females (Table $1 \mathrm{~b}$ ), decreased significantly over the summer in both years (Table 1c), and was significantly higher near the boundaries than near the centre of the territories $\left(\chi_{1}^{2}=137.97, P<0.001\right)$.

We examined the effect of having a larger number of adult males (rRHP hypothesis) rather than or a larger total number of individuals belonging to all age and sex classes (GA hypothesis) on both the percentage of overlap areas and the area available for individual exclusive use experienced by each group in a neighbouring dyad (Table $2 \mathrm{a}$ and $\mathrm{b}$ ). Having a 
large number of adult males, instead of a larger number of total individuals, reduced the percentage of the area shared by the group (i.e. Overlap Index, Fig. 2a-b) and increased the relative mean area for individual exclusive use (Fig. 4a-b). Multi-model selection for both the Overlap and the relative mean area for individual exclusive use retained the balanced Male Index (Table 2a and b) as predictor for the best fitting model. Moreover we found that Study Site and Young Index had an impact on Overlap Index (Fig. 3) and on the mean area of individual exclusive use (Fig. 5) respectively (Table 2a and b). Finally the Null model for the Overlap Index as explanatory variable was also retained $(\triangle \mathrm{AICc}=1.95)$.

\section{Discussion}

This study demonstrates that space use strategies in Alpine marmots, both at the individual (i.e. mean area available for individual exclusive use) and at the group level (i.e. overlap areas between neighbouring groups), are mediated by the differences in the number of helpers among groups (i.e. the realized Resource Holding Potential) rather than by the total number of individuals present in each group (i.e. the Group Augmentation hypothesis).

Helper contribute to territory holding and maintenance against neighbours (Cockburn 1998). In our study we found that the amount of areas shared with neighbours decreased as the proportion of helpers in the group increases (Fig. 2a). Helpers also provided benefits at the individual level, as their proportion inside the group increased the mean area available for individual exclusive use (Fig. 4a). These results suggest both direct and indirect benefits deriving from helpers: larger mean areas available for individual exclusive use directly lead to greater pro capita resources (Tallents et al. 2012), while a higher rRHP would indirectly reduce neighbour social pressures on the whole group. 
Adult males are more involved in territory marking during the active season than other age and sex classes (Table 1). In particular, males scent-marked more frequently than females, and adult males scent-marked more frequently than yearling males. The function of scent marking might serve as intra-sexual competition inside the group (Jordan et al. 2011) and/or territoriality between groups (Heap et al. 2012). In according to previous work (Lenti Boero 1995) we found that Alpine marmots scent-marked mostly at the boundaries of the territory and that, in addition, the number of scent marking behaviour increased with the proportion of overlap areas among groups (Fig. 1). This result is in accordance with the territorial function hypothesis proposed for this behaviour in the whole genus Marmota (Barash 1989, see Armitage 2014 for a detailed description of the other possible function of scent marking behaviour). Scent marking is a costly behaviour (animals move and mark the entire territory) and its occurrence should somehow be balanced with the fat storing needs of this hibernating species (Arnold 1992). The consequence of such a cost can be also deduced by the seasonal variation of this behaviour in alpine marmots. Indeed the highest frequency of scent marking was observed just after the emergence from winter burrows, when the group territory boundaries start to be delineated (Table 1c). The decrease in the frequency of marking behaviour over the summer, in particular after the emergence of the pups in July, can be explained by the reproductive role played by this behaviour and/or by the variation of time spent performing other important behaviours. Whereas foraging seems to increase in August in Alpine marmot (Perrin et al. 1993a) its direct variation throughout the season has not being observed in other similar species (Marmota flaviventris: Armitage et al. 1996). An alternative possible reason explaining the seasonal decrease of scent marking may derive from the observed increase in body fat accumulation during the fall probably caused by a reduction in energy expenditure with the season (e.g. reducing foraging, exploration and other costly activities) that ultimately resolved in an increased stability of the territory (Perrin et al 1993b; Pasquaretta et al. 2012). 
Neither the number of individuals nor the proportion of adult males inside the group was related to variation in territory size. In accordance with a previous study (Lenti Boero 2003) we found that mean territory size was stable, and it did not vary between years or among periods.

Moreover, we also found no relationship between territory size and the presence of pups in a group. A possible explanation for the stability of territory size is related to the biological characteristics of Alpine marmots and the environment they inhabit. Hibernating mammals such as Alpine marmots should defend territories composed of high quality patches, with a high concentration of polyunsaturated fatty acids in the vegetation rather than increasing the size of their territory per se (Arnold 1992). It is possible that the concentration of their preferred foods is not uniformly distributed, as observed in other marmot species (Marmota caligata: Holmes 1984; Marmota flaviventris: Stallman \& Holmes 2002) and that the yearly variation of their preferred plant families (Bassano et al. 1996; Garin et al. 2008) influences the shape of the territories but not their size. Moreover altitude could also affect quality of available plants. Indeed, alpine meadows at higher altitude are physiologically younger and consequently enriched of $\alpha$-linolenic acid (Hawke, J.C. 1973) which has been demonstrated affecting hibernation and torpor in mammals (Ruf \& Arnold 2008). In accordance our results show that groups inhabiting alpine meadows at lower altitude share larger part of their territory with neighbours underlining the need of incorporating data on vegetation quality to increase our knowledge on inter group competition in this species.

Interestingly, presence of pups has no influence on overlap areas among groups, suggesting that rRHP hypothesis might be stronger than the actual motivation of the helpers to increase their inclusive fitness. Generally, the presence of pups seems to reduce the mean area available for individual exclusive use probably implying the existence of a trade-off mechanism between fitness and mean resource availability in a group (Vahl et al. 2007). 
Individual characteristics are also expected to influence territory size and shape (Boyer et al. 2010). In two recent works on copying styles (see Koolhaas et al. 1999) we showed that Alpine marmots present consistently repeatable behavioural traits (Costantini et al. 2012, Ferrari et al. 2013). Future research should investigate how space use could be affected by individual differences accounting for both the environment resource availability and density of the population (Dingemanse et al. 2004).

In conclusion, our findings suggest a direct benefit associated with the presence of helpers in a group that results in the active maintenance of territory boundaries, in an increase of the mean individual area available for exclusive use, and in a reduction of neighbour social pressures on the group. However, it should be pointed out that the potential benefits deriving from the presence of helpers in a group might be outweighed by interference competition for food among members of a group (Vahl et al. 2007), or by possible costs for the dominant male of having a larger pool of possible competitors in the group. Indeed the probability of dominant male persistence in a group has been shown to drastically drop down when helpers are more than three in Alpine marmots (Allainé \& Theuriau 2004). 


\section{Acknowledgments}

Acknowledgements - we are grateful to: N. Martinet for helping us collect data in 2009. We thank B. Bassano for his constant support to the long term Alpine marmot research project in the Gran Paradiso National Park.We are grateful to the Surveillance Service of the park for logistc support and in particular to park wardens W. Vallet and M. Nicolino for their help during field work. This research was made possible thanks to funds from the Gran Paradiso National Park, the Department of Earth and Environmental Sciences (Zoology section), University of Pavia, the Natural Sciences and Engineering Research Council, and the Canada Research Chair Committee to D.R. C.P. was financially supported by a Doctoral grant from University of Pavia (Italy). C.F. was supported by a "Bourse d'excellence pour les cycles supérieurs de l'Université du Québec à Montréal (Canada)".

\section{Ethical standards}

The study complied with Canadian law regarding animal experiments (Comité Institutionnel de Protection des Animaux, protocol no. 615). The methods used to live-capture and mark marmots used in this study are in line with the Italian law. The capture and marking protocol has been authorized by the Gran Paradiso National Park authority after obtaining official approval by ISPRA (The Italian Institute for Environmental Protection and Research). 


\section{References}

Adams, E.S. (2001). Approaches to the study of territory size and shape. Annu. Rev. Ecol. Syst. 32: $277-303$.

Akaike H (1985) Prediction and entropy. In: Atkinson AC, Fienberg SE (eds) A celebration of statistics. Springer, New York, pp 1-24

Allainé, D. (2000). Sociality, mating system and reproductive skew in marmots: evidence and hypotheses. Behav. Processes 51: 21-34.

Allainé, D. (2004). Sex ratio variation in the cooperatively breeding alpine marmot Marmota marmota. Behav. Ecol. 15: 997-1002.

Allainé, D. \& Theuriau, F. (2004). Is there an optimal number of helpers in alpine marmot family groups? Behav. Ecol. 15: 916-924.

Altmann, J. (1974). Observational study of behaviour: sampling methods. Behaviour 49: 227267.

Armitage, K.B. (1976). Scent marking by yellow-bellied marmots. J. Mamm. 57:583-584

Armitage, K.B., Salsbury, C.M., Barthelmess, E.L., Gray, R.C. \& Kovach, A. (1996). Population time budget for the yellow-bellied marmot. Ethol. Ecol. Evol. 8: 67-95

Armitage, K.B. (2014). Marmot biology. Sociality, Individual Fitness and Population Dynamics. Cambridge University Press. Cambridge. Pag 186:191

Arnold, W. (1990). The evolution of marmot sociality: I. Why Disperse Late? Behav. Ecol Sociobiol. 27: 229-237.

Arnold, W. (1992). Adaptation to the cold. The physiology of marmot hibernation proceedings of the 1st int. symp. on Alpine marmot and genera Marmota. Torino

Arnold, W. \& Dittami, J. (1997). Reproductive suppression in male alpine marmots. Anim. Behav. 53: 53-66. 
Barash, D.P. (1989). Marmots: Social Behavior and Ecology. Stanford Univ. Press, Stanford, pp. 104-105.

Barton, K. (2009). MuMIn: multi-model inference. R package version 0.12.2/r18

Bassano, B., Peracino, V. \& Montacchini, F. (1996). Food habits of Alpine marmot (Marmota marmota) in Proceedings of the Second International Conference on Marmots: Biodiversité chez les Marmottes / Biodiversity in Marmots. International Marmot Network, Aussois (France) pp: 135-140.

Bel, M.C., Porteret, C. \& Coulon, J. (1995). Scent deposition by cheek rubbing in the Alpine marmot (Marmota marmota) in the French Alps. Can. J. Zool. 73: 2065-2071.

Benadi, G., Fichtel, C. \& Kappeler, P. (2008). Intergroup Relations and Home Range Use in Verreaux's Sifaka (Propithecus verreauxi). Am. J. Primatol. 70: 1-10.

Bergmüller, R., Johnstone, R., Russell, A. \& Bshary, R. (2007). Integrating cooperative breeding into theoretical concepts of cooperation. Behav. Processes 76: 61-72.

Blumstein, D.T. \& Armitage, K.B. (1999). Cooperative breeding in Marmots. Oikos 84: 369382.

Börger, L., Franconi, N., De Michele, G., Gantz, A., Meschi, F. \& Manica, A. (2006). Effects of sampling regime on the mean and variance of home range size estimates. J. Anim. Ecol. 75: $1393-1405$.

Boyer, N., Réale, D., Marmet, J., Pisanu, B. \& Chapuis, J.L. (2010). Personality, space use and tick load in an introduced population of Siberian chipmunks Tamias sibiricus. J. Anim. Ecol. 79: $538-547$.

Brady, K.M. \& Armitage, K.B. (1999). Scent marking in Yellow-bellied marmot. Ethol. Ecol. Evol. 11: 35-47.

Brashares, J.S. \& Arcese, P. (1999). Scent marking in a territorial African antelope: I. The maintenance of borders between male oribi. Anim. Behav. 57: 1-10. 
Bruintjes, R. \& Taborsky, M. (2008). Helpers in a cooperative breeder pay a high price to stay: effects of demand, helper size and sex. Anim Behav. 75: 1843-1850.

Burnham K.P. \& Anderson D.R. (2002). Model selection and multimodel inference: a practical information-theoretic approach, 2nd edn. Springer, New York

Calenge, C. (2006). The Package adehabitat for the R Software: a Tool for the Analysis of Space and habitat Use by Animals. Ecol. Modell. 197: 516-219.

Cockburn, A. (1998). Evolution of helping behavior in cooperatively breeding birds. Annu. Rev. Ecol. Syst. 29: 141-177.

Crofoot, M.C., Gilby, I.C., Wikelski, M.C. \& Kays, R.W. (2008). Interaction location outweighs the competitive advantage of numerical superiority in Cebus capucinus intergroup contests. Proc. Natl. Acad. Sci. U. S. A. 105: 577-581.

Crofoot, M.C., Lambert, T.D., Kays, R.W. \& Wikelski, M.C. (2010). Does watching a monkey change its behaviour? Quantifying observer effects in habituated wild primates using automated radiotelemetry. Anim. Behav. 80: 475-480.

Costantini, D., Ferrari, C., Pasquaretta, C., Cavallone, E., Carere, C., von Hardenberg, A. \& Réale, D. (2012). Interplay between plasma oxidative status, cortisol and coping styles in wild alpine marmots, Marmota Marmota. J. Exp. Biol. 215: 374-383.

Dingemanse, N.J., Both, C., Drent, P.J., \& Tinbergen, J.M. (2004). Fitness consequences of avian personalities in a fluctuating environment. Proc. R. Soc. London, Ser. B Biol. Sci. 271: $847-852$.

Ferrari, C., Bogliani, G. \& von Hardenberg, A. (2009). Alpine marmots (Marmota marmota) adjust vigilance behaviour according to environmental characteristics of their surrounding. Ethol. Ecol. Evol. 21: 355-364.

Ferrari, C., Pasquaretta, C., Bassano, B. \& von Hardenberg, A. (2012). Intraspecific killing and cannibalism in adult Alpine marmots Marmota marmota . Ethol. Ecol. Evol. 24: 388-394. 
Ferrari, C., Pasquaretta, C., Carere, C., Cavallone, E., von Hardenberg, A. \& Réale, D. (2013). Testing for the presence of coping style in wild mammals. Anim. Behav. 6: 1385-1396.

Fieberg, J. \& Kochanny, C.O. (2005). Quantification of home range overlap: the importance of the Utilization Distribution. J. Wildl. Manage. 69: 1346-1359.

Fieberg, J. (2007). Kernel density estimators of home range use: smoothing and the autocorrelation red herring. Ecology 88: 1059-1066.

Gaston, A.J. (1978). The evolution of group territorial behavior and cooperative breeding. Am Nat 112:1091-1099.

Garin, I., Aldezabal, A., Herrero, J., García-Serrano, A. \& Remón, J.L. (2008). Diet selection of the Alpine marmot (Marmota marmota) in the Pyrenees. Rev. Écol. 63: 383-390.

Gese, E.M., \& Ruff, R.L. (1997). Scent-marking by coyotes, Canis latrans: the influence of social and ecological factors. Anim. Behav. 54: 1155-1166.

Gittleman, J.L. \& Kot, M. (1990). Adaptation: statistics and a null model for estimating phylogenetic effects. Syst. Zool. 39: 227-241.

Gosling, L.M. \& Roberts, S.C. (2001): Scent-marking by male mammals: cheat-proof signals to competitors and mates. Adv. Study Behav. 30: 169-217.

Hadfield, J.D. (2010). MCMC methods for Multi-response Generalized Mixed Effect Models: The MCMCglmm R Package. J. Stat. Softw. 33: 1-22.

Hackländer, K., Mostl, E. \& Arnold, W. (2003). Reproductive suppression in female Alpine marmots, Marmota marmota. Anim. Behav. 65: 1133-1140.

Hackländer, K. \& Arnold, W. (2012). Litter sex ratio affects lifetime reproductive success of free-living female Alpine marmots Marmota marmota. Mamm. Rev. 42: 310-313.

Hamilton, W.D. (1964). The genetical evolution of social behaviour. J. Theor. Biol. 7: 17-52.

Hawke, J.C. (1973). Lipids, in Chemistry and Biochemistry of Herbage (Butler, G.W., and Baily, R.W., eds.) Vol. 1, pp. 213-263, Academic Press, London. 
Heap, S., Byrne, P. \& Stuart-Fox, D. (2012). The adoption of landmarks for territorial boundaries. Anim. Behav. 83: 871-878.

Hemson, G.P., Johnson, A., Kenward, S.R., Ripley, R. \& Macdonald, D. (2005). Are kernels the mustard? Data from global positioning system (GPS) collars suggests problems for kernel home-range analyses with least-squares cross-validation. J. Anim. Ecol. 74: 455-463.

Holmes, W.G. (1984). Predation risk and foraging behavior of the hoary marmot in Alaska. Behav. Ecol. Sociobiol. 15: 293-301.

Jordan, N.R., Mwanguhya, F., Kyabulima, S., Rüedi, P. \& Cant, M.A. (2010). Scent marking within and between groups of wild banded mongooses. J. Zool. 280: 72-83.

Jordan, N.R., Mwanguhya, F., Furrer, R.D., Kyabulima, S., Rüedi, P. \& Cant, M.C. (2011). Scent marking in wild banded mongooses: 2. Intrasexual overmarking and competition between males. Anim. Behav. 81: 43-50.

Kernohan, B.J., Gitzen, R.A. \& Millspaugh, J.J. (2001). Analysis of animal space use and movements. Radio tracking animal populations, Academic, San Diego, California pp. 125166.

Kokko, H., Johnstone, R.A. \& Clutton-Brock, T.H. (2001). The evolution of cooperative breeding through group augmentation. Proc. R. Soc. B 268: 187-196.

Koolhaas, J.M., Korte, S.M., De Boer, S.F., Van Der Vegt, B.J., Van Reenen, C.G., Hopster, H., De Jong, I.C., Ruis, M.A. \& Blokhuis, H.J. (1999). Coping styles in animal: current status in behavior and stress-physiology. Neurosci. Biobehav. Rev. 23: 925-935.

Lazaro-Perea, C. (2001): Intergroup interactions in wild common mamosets, Callithix jacchus: territorial defence and assessment of neighbours. Anim. Behav. 62: 11-21.

Le Vin A.L., Mable, B.K., Taborsky, M., Heg, D. \& Arnold, K.E. (2011). Individual variation in helping in a cooperative breeder: relatedness versus behavioural type. Anim. Behav. 82: 467477. 
Lenti Boero, D. (1995). Scent deposition Behaviour in Alpine Marmots (Marmota marmota L.): its Role in Territorial Defence and Social Communication. Ethology 100: 26-38.

Lenti Boero, D. (2003). Long-term dynamics of space and summer resource use in the alpine marmot (Marmota marmota L.). Ethol. Ecol. Evol., 15(4), 309-327.

Maher, C.R. (2004). Intrasexual territoriality in woodchucks (Marmota monax). J. Mammal. 85: 1087-1094.

Maher, C.R. (2009). Genetic relatedness and space use in a behaviorally flexible species of marmot, the woodchuck (Marmota monax). Behav. Ecol. Sociobiol. 63: 857-868.

Martin, P. \& Bateson, P. (1993). Measuring behaviour: an introductory guide, 2nd edition. Cambridge University Press, Cambridge, pp. 6-22.

Pasquaretta, C., Bogliani, G., Ranghetti, L., Ferrari, C. \& von Hardenberg, A. (2012). The Animal Locator: a new method for accurate and fast collection of animal locations for visible species. Wildlife Biol. 18: 1-13.

Perrin, C., Coulon, J. \& Le Berre, M. (1993a): Social behaviour of alpine marmots (Marmota marmota): seasonal, group, and individual variability. Can. J. Zool. 71: 1945-1953.

Perrin, C., Allainé, D. \& Le Berre, M. (1993b). Socio-spatial organization and activity distribution of the Alpine marmot (Marmota marmota): Preliminary results. Ethology 93: 2130.

Pinheiro, J.C. \& Bates, D.M. (2000). Mixed-Effects Models in S and S-PLUS. Springer, USA.

Ralls, K. (1971). Mammalian Scent Marking. Science 171: 443-449.

Ruf, T., \& Arnold, W. (2008). Effects of polyunsaturated fatty acids on hibernation and torpor: a review and hypothesis. American Journal of Physiology-Regulatory, Integrative and Comparative Physiology, 294: 1044-1052.

Seaman, D.E. \& Powell, R.A. (1996). An evaluation of the accuracy of kernel density estimators for home range analysis. Ecology 77: 2075-2085. 
Sillero-Zubiri, C. \& Macdonald, D.W. (1998). Scent-marking and territorial behaviour of Ethiopian wolves Canis simensis. J. Zool. 245: 351-361.

Solomon, N.G. \& French, J.A. (1997). Cooperative breeding in mammals. Cambridge University Press. Cambridge.

Stallman, E.L. \& Holmes, G.W. (2002). Selective Foraging and Food Distribution of HighElevation Yellow-Bellied Marmots (Marmota flaviventris). J. Mammal. 83: 576-584.

Stamps, J.A. (1984). Growth costs of territorial overlap: experiments with juvenile lizards (Anolis aeneus). Behav. Ecol. Sociobiol. 15: 115-119.

Taborsky, B., Arnold, C., Junker, J. \& Tschopp, A. (2012). The early social environment affects social competence in a cooperative breeder. Anim. Behav. 83: 1067-1074.

Tallents, L.A., Randall, D.A., Williams, S.D. \& Macdonald, D.W. (2012). Territory quality determines social group composition in Ethiopian wolves Canis simensis. J. Anim. Ecol. 81: 24-35.

Vahl, W.K., Van Der Meer, J., Meijer, K., Piersma, T. \& Weissing, F.J. (2007). Interference competition, the spatial distribution of food and free-living foragers. Anim. Behav. 74: 14931503.

Vogt, K., Zimmermann, F., Kölliker, M., \& Breitenmoser, U. (2014). Scent-marking behaviour and social dynamics in a wild population of Eurasian lynx Lynx lynx. Behav. process, 106, 98-106.

Worton, B.J. (1989). Kernel methods for estimating the utilization distribution in home-range studies. Ecology 70: 164-168.

Worton, B.J. (1995). Using Monte Carlo Simulation to Evaluate Kernel-Based Home Range Estimators. J. Wildl. Manage. 59: 794-800.

Zelenka, G. (1965). Observations sur l'ecologie de la marmotte des alpes. La Terre et la Vie 19: 238-256. 


\section{Figure legends}

Figure 1.

Relationship between the proportion of overlap areas and the proportion of scent-marking behaviours for each group in Alpine marmots at Orvielles, Gran Paradiso National Park, Italy. Best fitting regression line (solid dark) and the 95\% confidence interval around the estimated line (shaded grey area) are provided.

Figure 2.

Relationship between a) balanced Male Index and b) Group Index on the relative shared area (i.e. Overlap Index) calculated for each group dyad in Alpine marmots at Orvielles, Gran Paradiso National Park, Italy. When balanced Male Index is higher than 1 , the first group has a higher proportion of adult males than the second one. Similarly when Group Index is higher than 1 the first group has a larger number of total individuals than the second one. When the Overlap Index is negative, the first group shares less territory than the second one involved in the dyad. Best fitting regression line (solid dark) and the $95 \%$ confidence interval around the estimated line (shaded grey area) are provided.

Figure 3.

Differences in the overlap area shared by each dyad (Overlap Index) for groups inhabiting low and high study sites in Alpine marmots at Orvielles, Gran Paradiso National Park, Italy. Low site refers to overlap index between families collected in the area located at about 2100 m.a.s.l. while high site to overlap index between families collected in the area located at about 2300 m.a.s.1.. 
The boxplots show medians, quartiles, and 5th and 95th percentiles. Real points are provided in the figure.

Figure 4.

Relationship between a)balanced Male Index and b) Group Index on the Relative Area of Exclusive Use for each group dyad in Alpine marmots at Orvielles, Gran Paradiso National Park, Italy. When balanced Male Index is higher than 1, the first group has a higher proportion of adult males than the second one. Similarly when Group Index is higher than 1 the first group has a larger number of total individuals than the second one. When the Relative Area of Exclusive Use is positive, individuals of the first group have larger area for exclusive use than individuals belonging to the second one. Best fitting regression line (solid dark) and the $95 \%$ confidence interval around the estimated line (shaded grey area) are provided.

\section{Figure 5.}

Influence of pups presence (Young Index) on the Relative Area of Exclusive use. When the Relative Area of Exclusive Use is positive, individuals of the first group (A) have larger area for exclusive use than individuals belonging to the second one (B). Four cases are represented: A having no young and $\mathrm{B}$ having young (A_no - B_yes); $\mathrm{A}$ and $\mathrm{B}$ both having no young (A_no B_no); A and B both having young (A_yes - B_yes); A having young and B having no young (A_yes - B_no). The boxplots show medians, quartiles, and 5th and 95th percentiles. Real points are provided in the figure. 
Table 1. Frequencies of scent-marking behaviours for a) age, b) sex, and c) period in Alpine marmots in the Orvieilles population, Gran Paradiso National Park, in 2009 and 2010. Estimated posterior means and their 95\% credibility intervals (Lower and Upper HPD) were obtained from three Bayesian mixed-models with individual identity nested in group and year as random effect.

\begin{tabular}{lccc}
\hline & Posterior Mean & Lower & Upper \\
& & HPD 95\% & HPD 95\% \\
\hline a) & 0.057 & 0.044 & 0.073 \\
Yearling & 0.001 & 0 & 0.004 \\
Pup & 0.015 & 0.010 & 0.024 \\
\hline b) & & & 0.059 \\
Male & 0.040 & 0.013 & 0.037 \\
Female & 0.022 & 0.026 & 0.121 \\
\hline c) & & & 0.047 \\
Period 1 (Post-hibernation) & 0.092 & 0.065 & 0.028 \\
Period 2 (Pups emergence) & 0.043 & 0.028 & \\
Period 3 (Pre-hibernation) & 0.020 & & \\
\hline
\end{tabular}


Table 2. Model selection with Akaike's information criterion corrected for small sample size (AICc) for a) Overlap Index and b) the Relative Area for exclusive use. Full and null models are presented with the three best models considered for each analysis. Both models present the balanced Male Index (balanced_M_Index), the Group Index (G_Index), their interaction, Young Index (Y_Index) ans study site (Site) as fixed effect. Year and dyad identity were included as random effects. Selected models are shown in bold. Number of parameters $(K)$, differences between AICc ( $\triangle \mathrm{AICc})$, probability that the model is the best among candidate models $(\mathrm{Wi})$ and comparison of the Wi of each model with the best one selected ER (Evidence Ratio) are shown.

\begin{tabular}{|c|c|c|c|c|c|}
\hline & $\bar{K}$ & AICc & $\Delta \mathrm{AICc}$ & $\mathbf{W i}$ & $\overline{\text { ER }}$ \\
\hline \multicolumn{6}{|l|}{ a) Overlap Index model } \\
\hline balanced_M_Index + Site & 7 & -64.2 & $\mathbf{0}$ & 0.242 & 1 \\
\hline Site & 6 & -63.4 & 0.87 & 0.156 & 1.55 \\
\hline balanced_M_index & 6 & -62.6 & 1.62 & 0.108 & 2.24 \\
\hline Null_model (intercept model only) & 5 & -62.3 & 1.95 & 0.091 & 2.66 \\
\hline balanced_M_Index + G_Index + balanced_M_Index:G_Index + Y_Index + Site & 10 & -53.4 & 10.82 & 0.001 & 242 \\
\hline \multicolumn{6}{|l|}{ b) Relative Area for Exclusive Use model } \\
\hline balanced_M_Index + Y_Index & 7 & 192.5 & $\mathbf{0}$ & 0.321 & 1 \\
\hline Y_Index & 6 & 193.4 & 0.97 & 0.198 & 1.62 \\
\hline balanced_M_Index & 6 & 194.8 & 2.31 & 0.101 & 3.18 \\
\hline Null_model (intercept model only) & 5 & 200.7 & 7.60 & 0.007 & 45.86 \\
\hline balanced_M_Index + G_Index + balanced_M_Index:G_Index + Y_Index + Site & 10 & 202.2 & 9.49 & 0.003 & 107 \\
\hline
\end{tabular}


Figure 1.

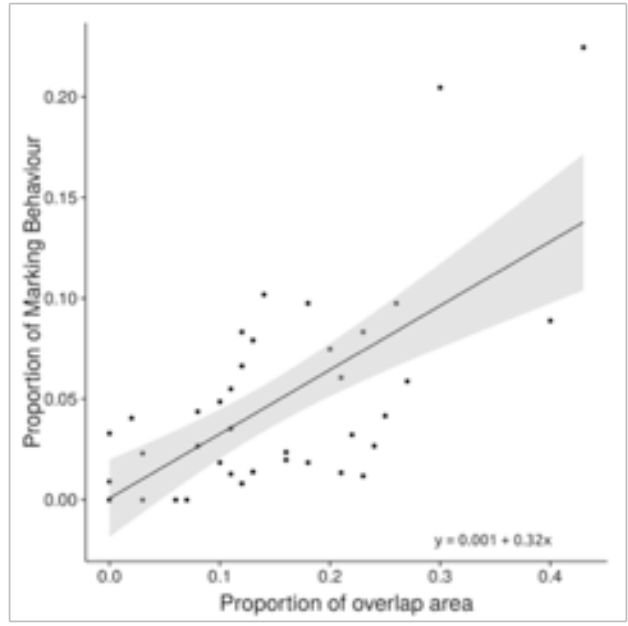


1 Figure 2.
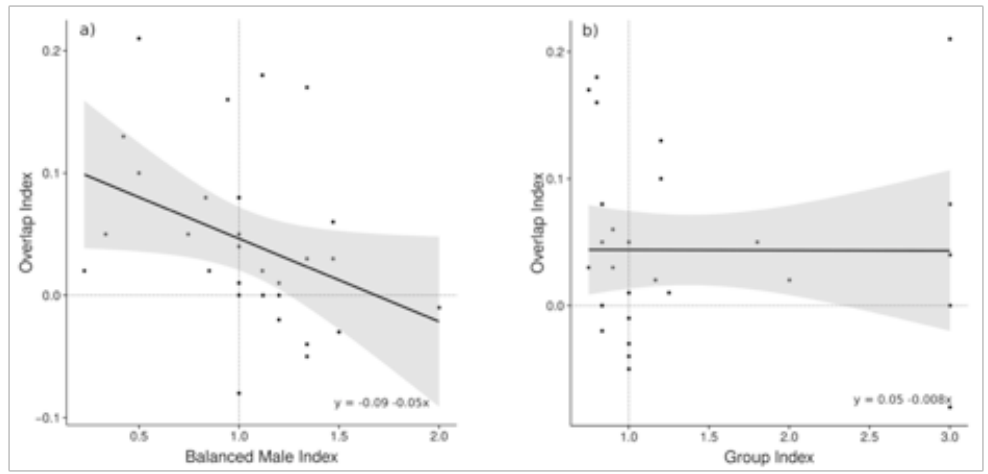
1 Figure 3.

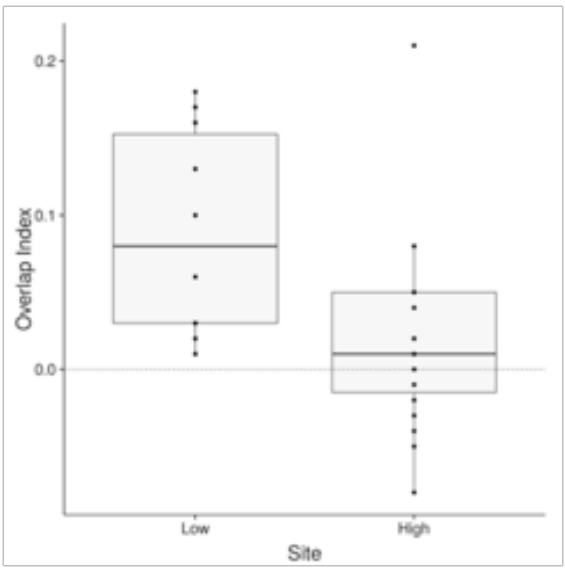


1 Figure 4.

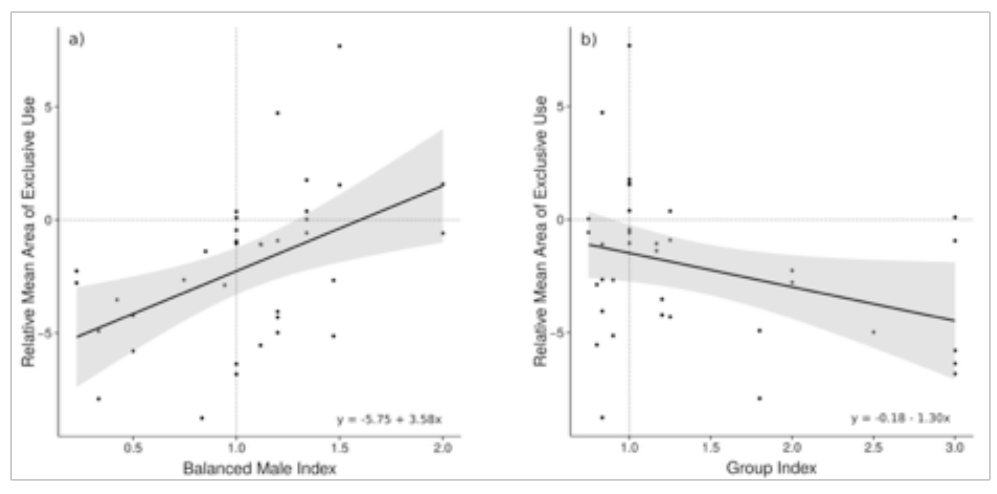


1 Figure 5.

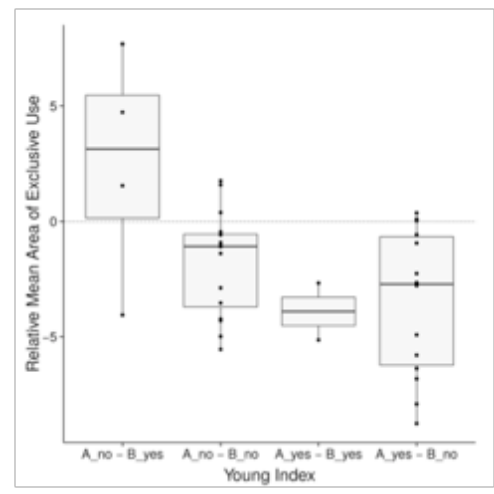

